\title{
RELATIONSHIP BETWEEN CELLULAR PHONES AND NON STRESS TEST
}

\author{
H. M. Youssef, M. R. El Shamy \& K. Anwar A. A. Alam \\ Department of Obstetrics \& Gynecology, \\ Mansoura University, Egypt
}

\section{ABSTRACT}

Objective : To determine the effects of electromagnetic fields produced by mobile phones on the Non stress test variables.

Study Design : This study was conducted in Mansoura university hospital, antenatal carc unit on one hundred normal pregnant women undergoing non stress test. The result of non stress tests were documented to be normal for twenty minutes in the absence of mobile phone in the examining room, then the tests were repeated while the subjects were holding the mobile (the same type) on ringing mode for 5 minutes.

Results : Electromagnetic fields emitted by mobile phones had no effects of acceleration or deceleration. However, there was no statistically significant increase in baseline fctal heart rate.

Conclusions : To our knowledge, these are the first results showing an increase in base line fetal heart rate under the effects of electromagnetic field emitted by cellular Phones, however further controlled randomized studies are necessary to detect a definitc correlation coefficient.

Key words : Electromagnetic fields, cellular phones, fetal heart ratc.

\section{INTRODUCTION}

The use of the fetal heart rate to assess fetal well being has become one of the standard obstetric practices (1). Considerable interest has built up in the use of cellular phones over the last years. Because safety is the main issue surrounding the use of any new modality in obstetrics and the effects of mobile phone on many biological processes as its negative effect on spermatogenesis and male infertility (2) our attention about the possible effects of electromagnetic fields on fetal heart rate were aroused.

Minimal description of the effects on fetal heart rate in the literature was found. this study is planned to determine any disturbnaces in the fetal heart rate under the effect of mobilephones by the use of non stress test (NST).

Non stress is one of the most common tests used for evaluation of fetal well-being ${ }^{(3)}$. This test is non invasive, easily performed and interpreted, and readily accepted by the patient ${ }^{(3)}$.

\section{MATERIALS \& METHODS}

Recording of the fetal heart rate under the effect of mobile electromagnetic ficld in 130 volunteers with uncomplicated pregnancy was done in the outpatient clinic in the antenatal care unit in Mansoura university hospital. thorough history taking, general and obstetric examinations were performed. Then counseling and fully informed written consents were obtained. Recording was done using non stress test for 20 minutes in absence of mobile phone in the room.

The results of non stress were interpreted by the physician. One hundred patients with normal non stress were exposed to electromagnetic field caused by ringing mobile for 5 minutes while doing non stress test.

Corresponding author : Hamed Youssef; E-mail: prof hamed@hotmail.com 
All patients were at term, singleton pregnancy with cephalic presentation.

Fetal heart rate analysis was blinded and analyzed depending on descripiton of fetal heat rate patterns by Nijhuis et al ${ }^{(4)}$. The analysis was done with respect to base line variation; acceleration and decelerations. The wicoxon matched - pairs signal ranks test was used to compare these variables.

\section{RESULTS}

These results denoted that no statistical significant differences in acceleration or deceleration occurred. However there was an increase in the basal fetal heart rate which was not statistically significant.

\section{DISCUSSION}

Although Mobile phones emit microwaves pulsed at extremely low frequency (800-1800 MHZ), it has been reported to produce subjective disorders such as headache, sleep irregularities, affect attention of the users, hematological and cardiovascular abnormalities ${ }^{(5)}$.

The increased use of mobiles in pregnant women nowadays encourages us to conduct such study. It was expected that there is an effect of mobile phones on fetal heart rate pattern due to close proximity of the fetus to the mobile phones during use. this effect depends on changing nerve conduction and cardiac contractility ${ }^{(6)}$.

Fortunately, our results indicated that electromagnetic fields emitte by mobile phones did not cause any statistically significant effects on base line fetal heart rate, acceleration and deceleration. We believe that the amniotic fluid may act as barrier against the electromagnetic field emitted by mobilephones.

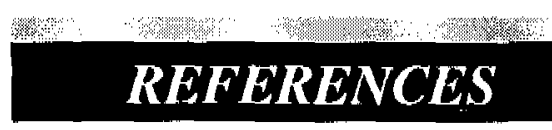

1- Poutamo J, Partanen K, Vaninnen Ret all MRI does not change fetal cardiotocographic Parametcrs. Prenat diagn 1998; 18: 1149-54.

2- Fejes, Z. Zavaczki, j et all: relationship between regular cell phone use and human semen quality. Abstracts presented at the $20 \mathrm{Th}$ annual meeting of the ESHRE, berlin, germany, 27-39 June 2004.

3- Willis DC, Blanco JD, et all the non stress test: criteria for the duration of fetal heart rate acceleration, J REPROD MED 1990; 35: 901-903.

4- Nijhuis JG, Precht HF, Martin CB et all is there behavioral states in the human fetus? Early human dev 1982: 6: 177-95.

5- Santimi R, Seigne M, Bonhnmme-Favre L et all. symptoms reported by mobile cellular Telephone users. Pathol boil 2001; 49: 222-6.

6- Vadeyer SH, Mooc RJ, Strachan BK et all. Effects of fetal magnetic resonance imaging on fetal heart rate patterns. AMJ Obstet Gynacol 2000; 182: 666-9.

Table I : Fetal heart rate characteristic during ringing mobile and no mobile (median and range).

\begin{tabular}{|c|c|c|c|}
\hline $\begin{array}{l}\text { Fetal heart rat } \\
\text { characteristics }\end{array}$ & Ringing Mobiles & No Mobile & $P$ Value \\
\hline $\begin{array}{l}\text { Base-line heart rate } \\
\text { (beats / minute) Mean \& range }\end{array}$ & $150(135-165)$ & $135(125-145)$ & 0.2874 \\
\hline $\begin{array}{l}\text { Accelerations } \\
15 \mathrm{~S} \text { (total no) Mean \& range }\end{array}$ & $5.1(0-12)$ & $4.8(0-11)$ & 0.4983 \\
\hline $\begin{array}{l}\text { Decelerations } \\
\text { (Total no) Mean \& range }\end{array}$ & $0.0(0.0)$ & $0.0(0.0)$ & 0.3067 \\
\hline
\end{tabular}

